\title{
Viral Quantitative Capillary Electrophoresis for Counting and Quality Control of RNA Viruses
}

\author{
Afnan Azizi
}

Research report submitted to the Department of Biochemistry, Microbiology and Immunology in partial fulfillment of the requirements for the course BCH 4040

\author{
University of Ottawa \\ Ottawa, Ontario, Canada
}

April 2012

(C) April 2012, Afnan Azizi 


\section{$\underline{\text { Abstract }}$}

The world of health care has witnessed an explosive boost to its capacity, within the past few decades, due to the introduction of viral therapeutics to its medicinal arsenal. As a result, a need for new methods of viral quantification has arisen to accommodate this rapid advancement in molecular virology and associated requirements for efficiency, speed, and quality control. Many current methods of viral quantification suffer from such issues as exclusion of significant segments of non-infective therapeutic viruses, erroneous detection due to contaminating material and required expertise, high cost, or handling time. Furthermore, none of these methods provide the means for concurrent determination of host DNA contamination, which is an important component of quality control in viral preparations. Therefore, we propose the use of a method of viral quantification, viral qCE, that we have specifically tailored for use with RNA viruses. We have used capillary electrophoresis (CE) to separate vesicular stomatitis virus (VSV), a promising oncolytic virus, from contaminating nucleic acids; hence quantifying viral titer by measuring RNA content of these virions using YOYO-1 fluorescent dye. We have further measured the amount of host DNA contamination contained in each sample to determine whether it adheres to regulatory guidelines. In addition, a number of frequently used laboratory procedures that could cause loss of viral titer were tested to estimate the amount of such loss. In comparison to viral qCE, a common infectivity-based assay (i.e. plaque-forming assay), produced a value for the virus concentration that was two orders of magnitude lower while NanoSight, a comparable method, yielded similar results. This method has the potential to measure the concentration of viral samples in a range of $10^{8}$ $10^{12}$ individual virus particles/mL. 


\section{$\underline{\text { Acknowledgments }}$}

I would like to thank Dr. Maxim Berezovski for his guidance throughout the project and helpful insights at critical times during its completion. In addition, I thank Gleb Mironov and Victor Okhonin for their contribution in the design and modeling of some of the experiments. I would also like to express my genuine gratitude to Darija Muharemagic, Ana Gargaun and Nasrin Khan for their mentorship and many constructive talks about my project and problems I was facing, specifically in matters regarding capillary electrophoresis. Many thanks go to Dr. John Bell and his group for preparing initial samples of the virus and continuous support in this area, as well as Alexey Chechik for helping with portions of the work. In addition, I thank Mohamed Wehbe for great companionship. 


\section{$\underline{\text { Table of contents }}$}

$\begin{array}{ll}\text { Abstract } & \text { ii }\end{array}$

Acknowledgements

Table of contents iv

List of tables $\quad$ V

List of figures vi vi vi vis

Contribution statement vii

$\begin{array}{ll}\text { Introduction } & 1\end{array}$

Materials and methods 6

$\begin{array}{lc}\text { Chemicals and reagents } & 6\end{array}$

Preparation of rRNA and DNA standards, virus lysis, RNase A and 6 $\mathrm{NaOH}$ treatments

$\begin{array}{ll}\text { Degradative conditions } & 7\end{array}$

$\begin{array}{ll}\text { Capillary electrophoresis } & 7\end{array}$

$\begin{array}{lr}\text { NanoSight measurements } & 8\end{array}$

Results and discussion $\quad 9$

$\begin{array}{ll}\text { Adaptation of Viral qCE to RNA viruses } & 9\end{array}$

Quantification of viral samples using viral qCE $\quad 15$

$\begin{array}{ll}\text { Degradation Analysis } & 21\end{array}$

$\begin{array}{ll}\text { Determination of host DNA contamination } & 24\end{array}$

$\begin{array}{ll}\text { Quantification of viral samples using NanoSight } & 27\end{array}$

$\begin{array}{ll}\text { Conclusion } & 28\end{array}$

$\begin{array}{ll}\text { References } & 29\end{array}$

Appendix 32 


\section{$\underline{\text { List of tables }}$}

1. Concentration of VSV samples, DNA contamination and percent degradation due to vortexing and ultrasonic treatment 


\section{$\underline{\text { List of figures }}$}

1. Schematic representation of viral qCE method 10

2. RNA standard curve $\quad 12$

3. Proteinase K and RNase A treatment of VSV samples 16

4. Localization of VSV in the capillary 19

5. Analysis of VSV degradation due to vortexing and ultrasonic treatment 23

6. Alkaline hydrolysis of RNA and DNA 25

7. DNA standard curve 26

A1. Lysis of VSV using heat treatment 32

A2. NanoSight analysis of a VSV sample 33 


\section{Contribution statements}

Conception: The preliminary idea of viral qCE based on separation of virus from nucleic acids was originally developed by Dr. Berezovski and Gleb Mironov (PhD student). The various possible ways to degrade RNA while keeping DNA intact were explored by Dr. Berezovski, Gleb Mironov, and me. In addition, I hypothesized the effects of the degradative conditions on the samples.

Experimental: Virus samples, initially used in developing the method, were prepared by Dr. Bell's group. The first batch analyzed in this work was prepared by Darija Muharemagic (PhD student) and the second one by Mohamed Wehbe (Honours student). I performed all the capillary electrophoresis experiments, and Alexey Chechik (Masters student) used NanoSight for determining the concentration of a virus sample.

Writing: This thesis was written by me and edited by Darija Muharemagic and Mohamed Wehbe. 


\section{$\underline{\text { Introduction }}$}

Novel therapeutic properties of various viral orders have led to a need for accurate methods of quantification and characterization of viral samples. The use of viruses as vehicles for antigens and gene therapy agents has increased due to a rapid progress in the field of molecular virology. Furthermore, extraordinary efforts have been made in the field of oncolytic viral therapy culminating in a number of ongoing phase II and III clinical trials with some encouraging results in effective targeting of tumours (Galanis, 2011; Breitbach et al, 2011). RNA oncolytic viruses possess a large share of this novel form of cancer therapy and many families of such viruses are being developed for destruction of tumour cells (Nguyen et al, 2009). In light of this exponential increase in production and use of viruses, it is necessary to improve upon current methods of quantification of viral titers to develop novel approaches that would enhance efficiency and accuracy of determination of virus concentration in a given sample.

Viral titers are usually quantified based on either their infectivity or particle numbers. Plaque-forming, fluorescent focus, endpoint dilution, and Pock assays belong to the former category of quantification methods (Hierholzer and Killington, 1996). Plaqueforming assay, as developed for mammalian cells by Dulbecco and Freeman (1959), is the most extensively used method for quantification of viral titers (Mocé-Llivina et al, 2004). It falls under the focal category of infectivity-based assays, in which viral titer is determined by counting the foci of infection caused by the virus. In contrast, quantal assays (the other type of infection-based assays, such as $\mathrm{TCID}_{50}$ ) detect an all-or-none occurrence of the infection in presence of various dilutions of the virus (Collins, 1991). Accordingly, plaque-forming assay is considered by many virologists to be highly 
accurate and reproducible. However, this method, similar to others based on infectivity, only quantifies the number of units (which may include more than one virus particle forming an aggregate) that are able and available to infect the cells, thus underestimating the number of viral particles present. Furthermore, this approach has the disadvantage of excluding all classes of non-infectious viruses, such as attenuated vaccine viruses, gene therapy vehicles, and other viruses that do not form plaques (Lambeth et al, 2005). Furthermore, plaque-forming assays are time consuming and require at least three days to perform (Hierholzer and Killington, 1996).

Other methods commonly employed for viral analysis are those that quantitatively yield the number of viral particles. Transmission electron microscopy (TEM), quantitative PCR (qPCR), flow cytometric counting, immunostaining and detection of viral nucleic acids are among such methods. While TEM can be used to accurately find the total number of viral particles and their concentration (Børsheim et al, 1990), the cost per sample and high level of expertise associated with its application deem it impractical for routine use at academic laboratories with limited resources or low-budget industrial operations. Quantitative PCR has also been broadly used to this end. The use of qPCR, however, not only poses intrinsic errors due to possibility of confounding effects of amplification of contaminating nucleic acids but also could be more erroneous in quantifying RNA viruses where the step of reverse transcription has to be added to the process (Bustin, 2002). Moreover, approaches based on quantifying the total viral proteins or quantitative detection of viral nucleic acids are also commonly used. Nonetheless, these methods are liable to produce overestimations as a result of non-specific detection of non-viral protein 
or nucleic acid impurities in samples. Likewise, many of less commonly used methods suffer from lack of specificity or sensitivity, as well as long preparation and assay times.

Moreover, while assays based on infectivity, such as plaque-forming assay, are reproducible and, indeed, necessary for many therapeutic applications, often it is important to determine the number of both infectious and non-infectious particles administered to patients. In addition, World Health Organization (WHO) has recommended that virus preparations from continuous cell lines contain no more than 10 ng per human dose of contaminating cellular DNA from the host (WHO, 2007). Specifically, viral preparations usually contain nucleic acid contaminations from two main sources: carried-over host cell DNA and viral nucleic acids from degradation of particles during the purification or storage of samples. As a result, devising a method capable of separating the virus titer from such contamination and quantifying each individually is highly desirable. To this end, we have tailored a method of viral quantification, viral quantitative capillary electrophoresis (viral qCE), for RNA viruses and have used it to address the above-mentioned issues.

Capillary electrophoresis (CE) provides a powerful platform for separating analytes based on their differential mobility within a capillary. The small diameter of the capillary ( $\mu \mathrm{m}$ range) in relation to its length ( $\mathrm{cm}$ range) and the resulting high surface area-to-volume ratio allows for the dissipation of heat caused from application of high electric potential (kV range) across the capillary (Karger, 1989). Therefore, CE presents an ideal opportunity for separating densely charged nucleic acids from other biological and nonbiological analytes within a water-based liquid phase and in a rapid, sensitive and reproducible manner. In particular, experiments can be conducted very efficiently using 
extremely small sample volumes (low $\mu \mathrm{L}$ range) in a relatively small time span (minutes) (McCord et al, 2008). Furthermore, large biological particles, up to and including eukaryotic cells, have been analyzed using CE and effectively separated based on their surface charge in buffers of appropriate $\mathrm{pH}$ (Kremser and Kenndler, 2004). Among these, viruses have formed a sizable portion of these biological samples owing to their small size and relative stability in high electric field conditions of CE. In fact, numerous features of viral biology, from isoelectric point to genome expulsion kinetics, have been studied using CE technology (Kremser and Kenndler, 2009). Since even at higher pH buffers viral surface proteins do not possess as high a charge density as nucleic acids, CE can easily be used to separate the viral population form nucleic acids (e.g. DNA) in the injected sample (Krylova et al, 2004). Thus, a major hurdle in determining the concentration of viral samples can be removed by taking advantage of charge-based separation of contaminating nucleic acids from virus particles.

We used a vesicular stomatitis virus strain, VSV- $\Delta 51$ (Jennerex, Canada), which has been shown to possess potent oncolytic properties (Cary et al, 2011) against a large number of potential target tumour types (Barber, 2005). VSV is a small bullet-shaped negativestrand RNA virus from the Rhabdoviridae family (Knipe and Howley, 2007). Its genome consists of about $11.9 \mathrm{~kb}$ of encapsidated ssRNA encoding for five proteins (Russell, 2006) and is approximately $200 \mathrm{~nm}$ in length and $70 \mathrm{~nm}$ in diameter (Cureton et al, 2010). VSV selectively attacks tumour cells by taking advantage of defects in the interferon pathway of many such cells (Balachandran and Barber, 2000). In fact, VSV is very sensitive to this pathway in normal cells (Russell, 2002) forming a basis for production of recombinant VSV strains, including VSV- $\Delta 51$, which have heightened 
sensitivity to innate immunity resulting in a better tumour selectivity over healthy cells (Stojdl et al, 2003). Subsequently, Recombinant DNA Advisory Committee of NIH has considered VSV for clinical trials at least on two occasions (U.S. DHHS, 2008a; U.S. DHHS, 2008b). Furthermore, VSV is being developed as a vaccine shuttle for an array of viral pathogens, such as HIV-1 (Clarke et al, 2006), Ebola virus (Geisbert et al, 2008), hepatitis B (Cobleigh et al, 2010) and C (Majid et al, 2006). In view of the significant therapeutic potential of VSV and due to its widespread use and well-characterized nature as a model virus for Rhabdoviridae (Russell, 2002), we applied the viral qCE method to determine the number of intact virus particles (ivp) in viral samples, amount of their DNA contamination, and degree of viral degradation due to a number of processes frequently used during sample handling. 


\section{Materials and methods}

Chemicals and reagents: Samples of purified vesicular stomatitis virus ( $\triangle 51-$ YFP) were originally provided by Jennerex Inc. (Ottawa, ON, Canada). More samples were subsequently produced, in house, using Vero cells (donated by the Bell lab) as described before (Diallo et al, 2012). The following chemicals were purchased: sodium borate decahydrate (cat. no. SX0355-1, EMD Chemicals, USA); anti-VSV-G antibody conjugated with DyLight ${ }^{\text {TM }} 488$ (cat. no. 600-441-386, Rockland Immunochemicals, USA); YOYO-1 dye (cat. no. Y3601, Invitrogen, USA); lambda DNA standard (cat. no. D1501, Promega, USA); RiboGreen ${ }^{\circledR}$ and Escherichia coli rRNA (16S and 23S) standard from the Quant-IT ${ }^{\mathrm{TM}}$ RiboGreen ${ }^{\circledR}$ RNA Assay Kit (cat. no. R11490, Invitrogen, USA); SYTO ${ }^{\circledR}$ RNASelect ${ }^{\mathrm{TM}}$ (cat. no. S3270, Invitrogen, USA); RNase A (cat. no. 21210, batch lot no. 4144128, Affymetrix, USA); Proteinase K (cat. no. BP1700-100, Fisher Scientific, Canada); bare silica capillary with O.D. $360 \mu \mathrm{m}$ and I.D. $75 \mu \mathrm{m}$ (cat. no. TSP075375, Polymicro Technologies, AZ, USA). All buffers and samples were prepared from nuclease-free de-ionized water using a Synergy UV system (cat. no. SYNSV00WW) supplied with a $13 \mathrm{kDa}$ cut-off, BioPak Point-of-Use ultrafilter (cat. no. CDUFBI001, Millipore, MA, USA).

Preparation of rRNA and DNA standards, virus lysis, RNase A and $\mathrm{NaOH}$ treatments: Samples of rRNA were prepared by serial 5-fold dilutions starting from the $100 \mu \mathrm{g} \mathrm{mL}{ }^{-1}$ stock solution in $25 \mathrm{mM}$ borax buffer. Samples of DNA standard were prepared in the same manner from a $100 \mu \mathrm{g} \mathrm{mL}^{-1}$ dilution of the $303 \mu \mathrm{g} \mathrm{mL}^{-1}$ stock solution. All virus samples were diluted to 20 times the provided stock concentration 
using $5 \mathrm{mM}$ borax buffer before further manipulation and analysis. To lyse the virus, VSV samples were incubated with $600 \mu \mathrm{g} \mathrm{mL} L^{-1}$ of proteinase $\mathrm{K}$ at $50^{\circ} \mathrm{C}$ for two hours. Alternatively, virus samples were incubated at $95^{\circ} \mathrm{C}$ for 4 hours to lyse them by denaturing the viral capsid proteins. Samples for RNase A treatment analysis were incubated at $60^{\circ} \mathrm{C}$ with $378 \mu \mathrm{g} \mathrm{mL}{ }^{-1}$ of RNase A (5830 units $\mathrm{mg}^{-1}$ ). In order to hydrolyse RNA for contaminating DNA determination, samples of proteinase K-lysed virus were incubated with a final concentration of $50 \mathrm{mM} \mathrm{NaOH}$ at $60^{\circ} \mathrm{C}$ for 60 minutes. DNA standard samples included a final concentration of $50 \mathrm{mM} \mathrm{NaOH}$ and were subjected to the same conditions as lysed viral samples. YOYO-1 dye and RiboGreen reagent were diluted in $25 \mathrm{mM}$ borax buffer and added to each sample to a final concentration of 2 $\mu \mathrm{M}$.

Degradative conditions: Viral samples were exposed to the following conditions to determine the amount of loss or degradation of virus titers. Extensive vortexing: $20 \mu \mathrm{L}$ of virus samples were continuously vortexed for 10 or 25 minutes at highest speed using an analog vortex mixer (cat. no. 58816-121, VWR, Canada). Sonication: $20 \mu \mathrm{L}$ of virus samples were placed in a Branson Ultrasonic Cleaner (Model 3510, Branson Ultrasonics Corporation, USA) for 5 or 15 minutes at room temperature.

Capillary Electrophoresis: A ProteomeLab ${ }^{T M}$ PA 800 system (Beckman Coulter, CA, USA) was used to perform all capillary electrophoresis laser-induced fluorescence analyses. Fluorophores were excited using $488 \mathrm{~nm}$ Argon Ion Laser source (Beckman Coulter, CA, USA), whose fluorescence was detected using a $520 \pm 10 \mathrm{~nm}$ filter. The data were acquired and analyzed using 32 Karat Software version 8.0 (Beckman Coulter, CA, 
USA). The electrophoresis was performed using a fused silica capillary with a total length of $59.1 \mathrm{~cm}$ and an effective length of $48.95 \mathrm{~cm}$ from point of injection to detection window. For electrokinetic separation experiments, a plug of $40 \mathrm{~nL}$ sample was injected into the capillary by applying a pressure pulse of 1.0 psi for 5 seconds. The analytes in the sample were separated by applying $25.1 \mathrm{kV}$ potential difference along the capillary resulting in an electric field of $424 \mathrm{~V} \mathrm{~cm}^{-1}$. To measure the total fluorescence of samples, a continuous plug was pushed through the capillary by applying 1.5 psi pressure for 10 minutes. The capillary was maintained at a temperature of $15^{\circ} \mathrm{C}$ at all times. The run buffer for all analyses was $25 \mathrm{mM}$ borax buffer; before each run, the capillary was rinsed by applying 20.0 psi of $0.1 \mathrm{M} \mathrm{HCl}, 0.1 \mathrm{M} \mathrm{NaOH}$, and $\mathrm{ddH}_{2} \mathrm{O}$ for 2 minutes each and 25 $\mathrm{mM}$ borax buffer for 4 minutes. All buffers and rinsing solutions were passed through a $0.2 \mu \mathrm{m}$ filter before use.

NanoSight measurements: A NanoSight LM10 system (NanoSight Ltd, UK) was used to perform concentration measurements on viral samples. Samples of VSV were diluted in $5 \mathrm{mM}$ borax buffer and $200-300 \mu \mathrm{L}$ of each sample was injected into the NanoSight instrument and analyzed using NTA 2.0 software. The calibration of the NanoSight system was carried out using polystyrene nanospheres of 100, 200 and $400 \mathrm{~nm}$ in diameter in various concentrations (Thermo Scientific, CA, USA). The NTA software was set to use 2000 frames for each measurement, whereby it calculated the size of particles present in each frame to determine the population of particles within a given size constraint, and thus, finding the concentration of virus particles in each sample. 


\section{Results and Discussion}

Adaptation of Viral qCE to RNA viruses: It was previously shown that viral qCE can be used to accurately determine the concentration of virus particles with DNA genomes (Mironov et al, 2011). Hence, it was desirable to extend the application of this method to RNA viruses and improve upon it by integrating a compatible method for quantification of contaminating host DNA. In principle, viral qCE relies on the differential mobility of negatively charged free nucleic acids and intact viral particles. The general scheme of the method is depicted in Figure $\mathbf{1}$ and can be summarized as follows. When the sample containing intact virus particles and contaminating nucleic acids from host cells and viral degradation is stained with an appropriate fluorescent dye and injected into the capillary, the two components are separated (Figure 1A). Depending on the $\mathrm{pH}$ of the buffer, virus particles may be slightly charged or neutral. In either instance, they would possess a much smaller charge density than nucleic acids in the sample and would travel faster than these towards the cathode. Virus particles in the sample are difficult to quantify directly due to lack of a proper standard, as well as complicated electropherogram patterns caused by formation of virus aggregates - visualized as spikes on the electropherogram - which are not suitable for reproducible quantitative analysis. To address these two issues, virus particles are lysed and the amount of naked RNA that is released form viral particles is measured by its comparison to a standard RNA curve (Figure 2). However, since the nucleic acid peak after lysis of virus particles includes contamination in the sample, the contamination level of the original sample needs to be subtracted from the final amount of RNA found in the lysed sample (Figure 1B). Furthermore, the amount of host DNA present in the original sample, which should not surpass the limit of $10 \mathrm{ng}$ per human 

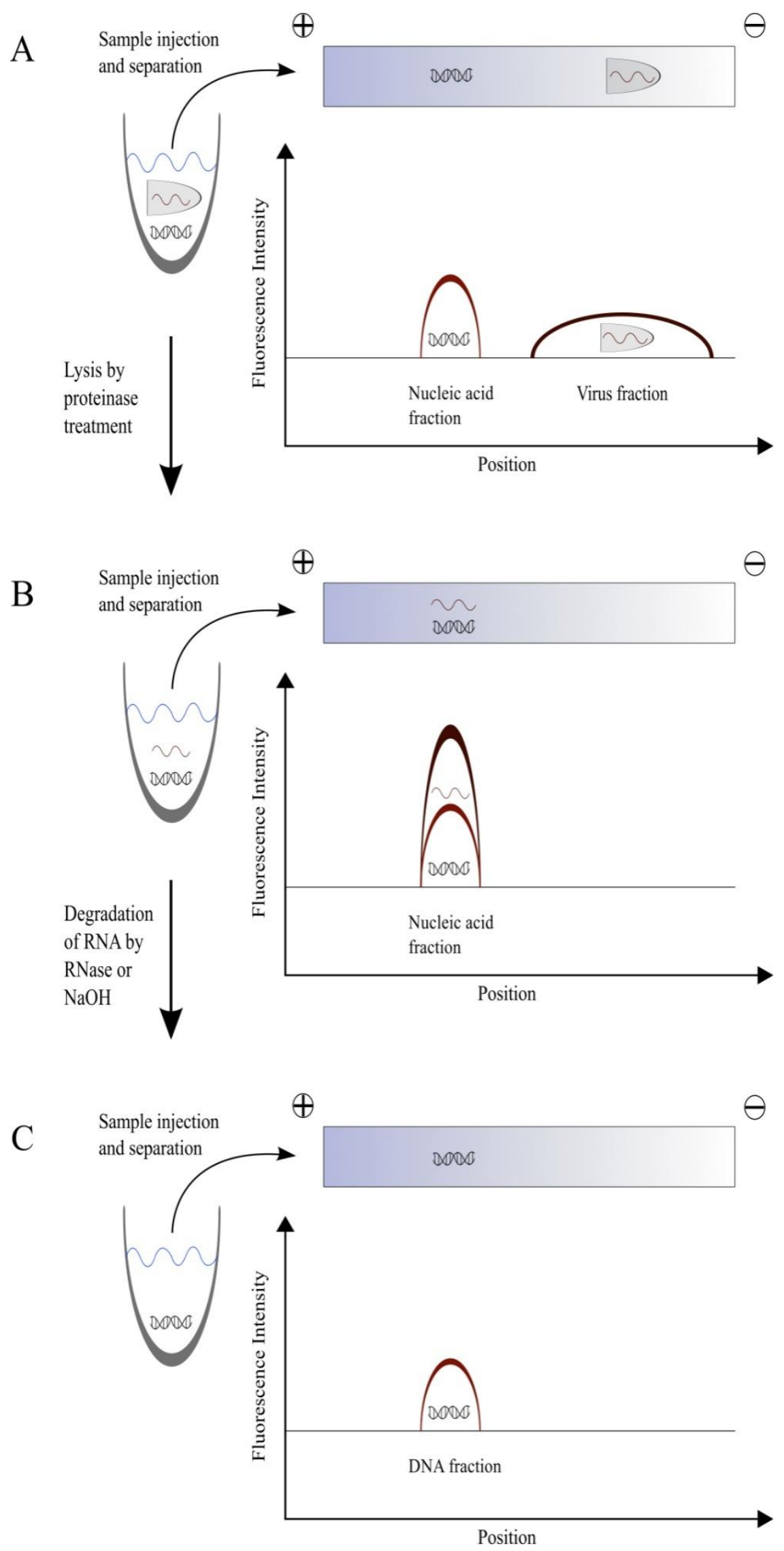
Figure 1. Schematic for applying viral qCE analysis to RNA viruses as exemplified by vesicular stomatitis virus (VSV). A) The sample is injected into the capillary and the virus is separated from contaminating nucleic acids. B) The viral particles in the sample are lysed using proteinase $\mathrm{K}$ and are injected into the capillary to determine the total amount of nucleic acids. C) This process is followed by treatment of the sample with $\mathrm{NaOH}$ to hydrolyse RNA molecules in the sample and obtain the amount of contaminating DNA from host cells. These fluorescence data are used to calculate the concentration of viral particles and DNA contamination in the sample as described in text. 


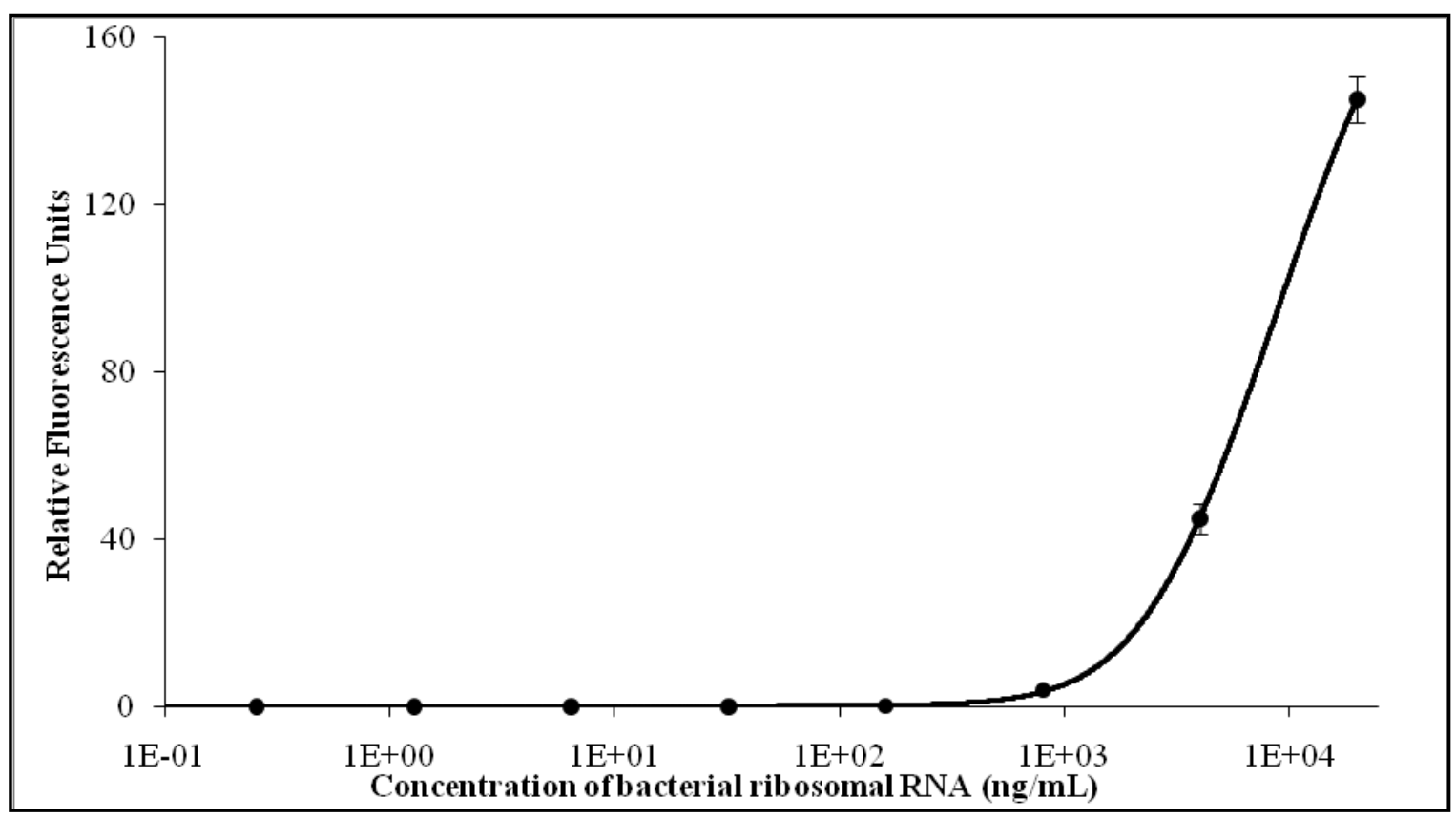

Figure 2. Increase in fluorescence of YOYO-1 dye bound to various concentrations of bacterial rRNA. Non-linear regression was used to fit a line to the data points, andit is used to interpolate the equivalent concentration of viral RNA based on the latter's fluorescence. 
dose, can be calculated from the nucleic acid peak remaining after treatment with sodium hydroxide (Figure 1C). In the present study, three nucleic acid binding dyes were tested for their compatibility with viral qCE. Of these dyes, SYTO RNASelect, a cell-permeant cyanine dye, was deemed impractical because it maintained much lower fluorescence intensity than its counterparts during the first stages of protocol development. Both RiboGreen and YOYO-1 have high quantum yield with more than 1000-fold increase in fluorescence upon binding to their target. While YOYO-1 is primarily used for staining dsDNA, it can bind other nucleic acids, such as RNA (Sotelo-Silveira et al, 2004) and ssDNA (Cosaet al, 2001). Both nucleic acid dyes have previously been used successfully to stain and identify encapsidated viruses in CE analysis (Mironov et al, 2011; Krylova et al, 2004; Kremser et al, 2004). Therefore, they were determined to be appropriate for this application since they would penetrate the viral capsid and would not dissociate or diffuse during the separation process. In our experiments, YOYO-1 demonstrated a slightly higher fluorescence signal than RiboGreen when bound to the ribosomal RNA standards. In addition, we found that RiboGreen selectively binds RNA and shows much lower sensitivity than YOYO-1 for the contaminating DNA fraction. Therefore, it was not as suitable for use in the final stage of our analysis with DNA alone. Due to these reasons and wider usage of YOYO-1, we selected this dye for our analysis. YOYO-1 is a symmetric, cell-impermeant cyanine dimer, which binds nucleic acids through bisintercalation (Johnson and Spence, 2010).

Proteinase K, a robust serine protease, was used to break down the viral proteins and lyse the virus. The main advantage of proteinase $\mathrm{K}$ is its ability to digest naturally folded proteins (Ebeling et al, 1974), which removes the need for introducing denaturing 
conditions in the samples prior to treatment; thereby, removing another potential source of error. In addition, the RNA molecule of VSV, like that of many other RNA viruses, is protected within a structure formed by nucleocapsid proteins. Therefore, to ensure that the dye could access the RNA of the virus unhindered and bind in a comparative manner to the standards, proteinase $\mathrm{K}$ digestion was chosen to remove nucleocapsid proteins and produce naked RNA. Moreover, we incubated the virus sample at $95^{\circ} \mathrm{C}$ to compare the efficacy of heat denaturation of viral proteins to proteinase $\mathrm{K}$ digestion. We observed that even after 4 hours of heat treatment a small peak corresponding to intact virus was still present (Figure A1). Complete lysis of viral particles in the sample and release of viral RNA were confirmed by the disappearance of the spiked peaks corresponding to the intact virus after proteinase $\mathrm{K}$ treatment. However, since the nucleic acid peak became much wider after lysis, it partially (or sometimes completely) overlapped with the area in which the viral peak would have been observed. Therefore, we performed further analysis of the lysed samples through RNase A treatment. RNase A is one of the most commonly used ribonucleases and can be used to digest various types of RNA molecules. It is known that nucleases cannot access the VSV RNA in its ribonucleoprotein form (i.e. when associated with nucleocapsid proteins) even if the viral capsid is removed (Rainsford et al, 2010). We treated our proteinase K lysed viral samples with RNase A and observed a complete disappearance of the wide RNA peak leaving behind a small peak corresponding to the residual DNA contamination (Figure 3B top). Disappearance of majority of the wide nucleic acid peak, including areas overlapping the viral region, indicates that all the RNA present in the lysed sample is naked and free of its $\mathrm{N}$ protein capsid. Conversely, the persistence of a small spiked peak in the viral region that was not 




Figure 3. Electrophoregrams corresponding to A) the viral sample before (bottom) and after (top) lysis using proteinase K, and B) RNase treatment of the intact sample (bottom) and lysed sample (top). See methods for lysis and RNase treatment conditions. 
removed after RNase A treatment of the heat-treated sample in Figure A1 implies that viral proteins have a relatively high resistance to heat treatment.

Quantification of viral samples using viral qCE: In principle, viral qCE relies on separation of nucleic acids from intact virus to facilitate quantification of the latter using laser-induced fluorescence of a nucleic acid-binding dye. In this method, intact virions were initially separated from free nucleic acids by $\mathrm{CE}$ to determine the degree of contaminating nucleic acids. Sequentially, the sample was lysed and separated under the same conditions using CE (Figure 3A). As a result, the relative amount of contaminating nucleic acids, including host DNA and RNA from viral degradation, before lysis to that of the total nucleic acids afterwards was determined. This relative amount (i.e. free nucleic acid fraction), $F$, is calculated by dividing the area underneath the graph of the free nucleic acid peak before lysis, $A_{f}$, by the area under the graph of the total nucleic acid peak after lysis, $A_{T}$

$$
F=\frac{A_{f}}{A_{T}}
$$

The concentration of RNA released from the virus was interpolated from the constructed rRNA calibration curve of Figure 2. The RNA calibration curve was constructed by measuring the total fluorescence of increasing concentrations of rRNA bound to YOYO1 dye (see Methods for details). A curve was fit to the recorded data using non-linear regression functionality of Microsoft Excel software (Microsoft corporation, USA) minimizing the square of differences between the theoretical and experimental data, to obtain the following relationship, 


$$
R F U=\exp \left(-327([R N A]+457)^{-0.56}-303([R N A]+129)^{1.1 \times 10^{-3}}+312\right)
$$

This theoretical relationship had a squared distance from experimental data of 0.3 . The fraction, corresponding to free nucleic acids (equation 1), was subtracted from the relative fluorescence of the total lysed viral sample and the concentration of RNA released from the virus was interpolated from the constructed rRNA calibration curve,

$$
\left[R N A_{v}\right]=f^{-1}(R F U \cdot(1-F))
$$

where $\left[R N A_{v}\right]$ is the concentration of viral RNA in $\mathrm{ng} \mathrm{mL}^{-1}, R F U$ is the fluorescence of total nucleic acids after lysis and $F$ is the fraction of free nucleic acids. Subsequently, the concentration of the virus was calculated according to the following formula:

$$
[\text { virus }]=\frac{N_{a} \cdot\left[R N A_{v}\right]}{10^{9} \cdot M M\left(R N A_{v}\right)}
$$

where [virus] is concentration of intact virions in the sample in ivp $\mathrm{mL}^{-1}, N_{A}$ is Avogadro's constant, $6.022 \times 10^{23} \mathrm{~mol}^{-1},\left[R N A_{v}\right]$ is calculated concentration of released viral RNA, after subtracting the free nucleic acid fraction, in $n g \mathrm{~mL}^{-1}$ and $M M\left(R N A_{v}\right)$ is the molecular mass of the viral RNA, which is $3.84 \times 10^{6} \mathrm{~g} \mathrm{~mol}^{-1}$ for VSV.

Moreover, an antibody specific to an extracellular epitope of VSV G protein, which is located on the viral capsid, was used to validate peak designation for the virus fraction. The peak of fluorescently tagged anti-VSV G antibody shifted upon binding to VSV particles demonstrating a higher retention time. Since the virus, the antibody and their complexes are incubated at physiological $\mathrm{pH}$ and are then subjected to somewhat higher $\mathrm{pH}$ conditions during the run, they could be considered to have neutral or slightly 
negative charges. The shift in the position of the fluorescent peak corresponds to the decrease in electrophoretic mobility of neutral or slightly negative analytes as their size increases. Furthermore, the shape of the observed antibody-VSV complex and its retention time coincided with those of VSV stained with YOYO-1 fluorescent dye as demonstrated in Figure 4. Table 1 summarizes the results obtained from the analysis of two batches prepared in slightly different manners. In both cases, viral qCE yielded values two orders of magnitude higher than those obtained using plaque-forming assay, confirming the notion that this assay underestimates viral concentrations. However, the value found using viral qCE was close to that obtained from NanoSight, which, in principle, is similar to the former as it counts single particles, not infective units.

Viral qCE analysis of batch 1 was performed on a two-month-old sample of virus stored at $4^{\circ} \mathrm{C}$. According to unreported observations of samples from this batch, analyzed closer to the time of its production, it had fluorescence values 6-7 times higher than samples used for this report. However, those earlier samples were analyzed using other conditions and were not suitable for inclusion here. Nonetheless, taking those unreported observations into account, we hypothesize that the reason for similarity of concentration values for batch 1 and 2 found by viral qCE is degradation of virus particles in the former since the latter was analyzed from freshly prepared virus samples. Indeed, this would be in agreement with plaque-forming assay data since batch 1 has a concentration about 6 times higher than batch 2 . These results imply that whatever the reason for the difference of two orders of magnitude between viral $\mathrm{qCE}$ and plaque-forming assay, it is a systematic difference, which is reproducibly present in both methods. 


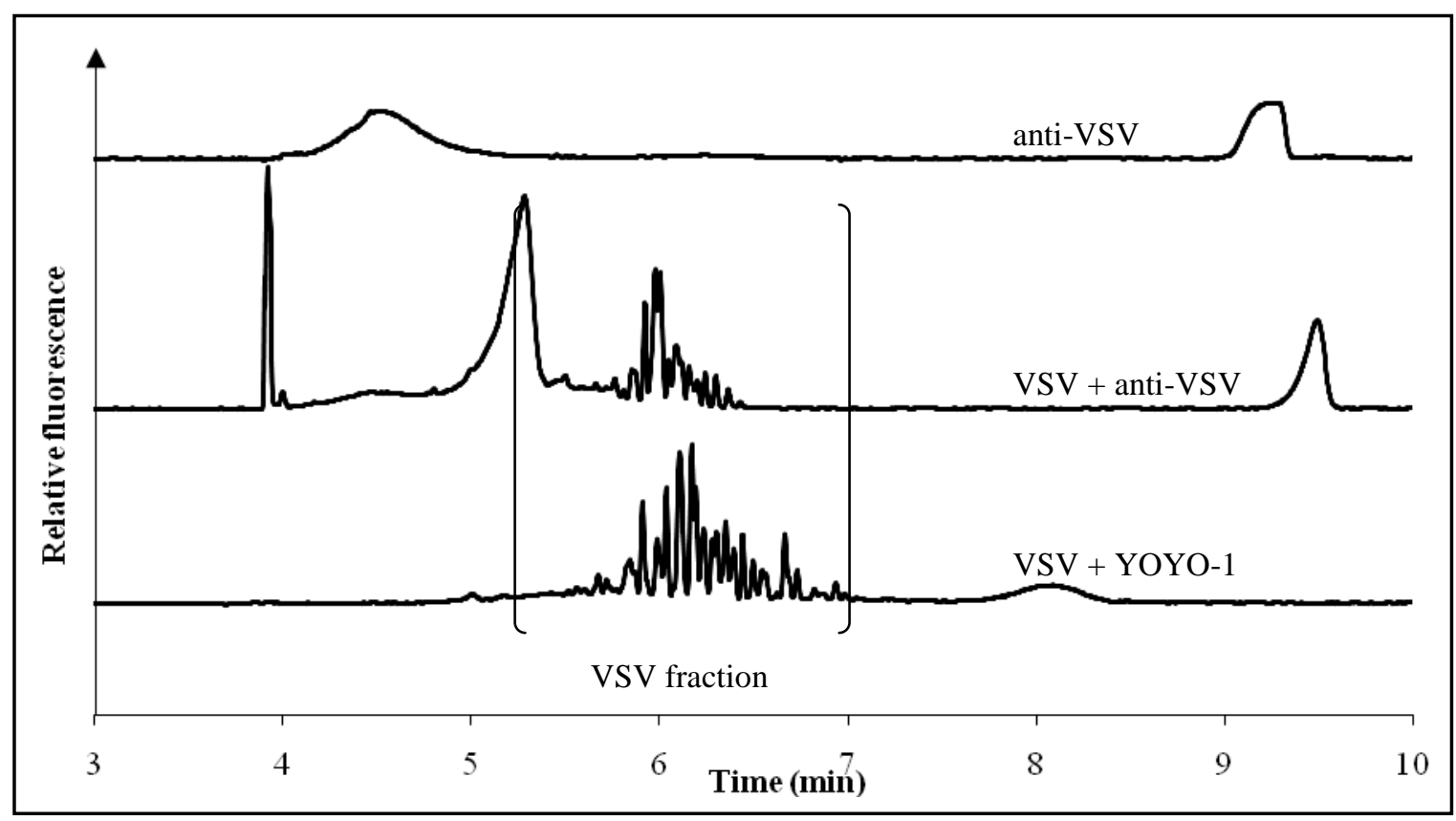

Figure 4. Fluorescently labeled anti-VSV-G antibody (top) reaches the detection window when bound to VSV (middle) at the same time (in brackets) as VSV alone when stained with YOYO-1 fluorescent dye (bottom). 
Table 1. Experimental results for various analyses performed on samples from two batches of VSV prepared with slight variations.

\begin{tabular}{|c|c|c|}
\hline Analysis & Batch 1 & Batch 2 \\
\hline \multicolumn{3}{|l|}{ Concentration } \\
\hline Viral qCE (ivp/mL) & $(9.5 \pm 0.5) \times 10^{12 a}$ & $(9.1 \pm 0.4) \times 10^{12}$ \\
\hline NanoSight (particles/mL) & $(1.7 \pm 0.2) \times 10^{13}$ & - \\
\hline Plaque forming assay (PFUs) & $1.0 \times 10^{11 a}$ & $1.6 \times 10^{10}$ \\
\hline Host DNA contamination $(\mathrm{ng} / \mathrm{mL})^{b}$ & - & $4100 \pm 30$ \\
\hline \multicolumn{3}{|l|}{ Degradation $(\%)^{b, c}$} \\
\hline Vortexing (10 min) & - & 22 \\
\hline Vortexing (25 min) & - & 41 \\
\hline Sonication $(5 \mathrm{~min})$ & - & 28 \\
\hline Sonication (15 min) & - & 32 \\
\hline \multicolumn{3}{|c|}{ a) These measurements were made two months apart from each other. } \\
\hline \multicolumn{3}{|c|}{ b) These analyses were not developed by the time batch 1 was finished. } \\
\hline c) Triplicates were not perfo & se samples due to la & f time. \\
\hline
\end{tabular}


Degradation Analysis: Viral qCE provides a facile way to investigate the extent of viral degradation due to various virus-handling procedures without the need for quantification of total amount of virus present in each sample after such degradative processes. Since this method is based on the separation of intact virus particles from free nucleic acids in each sample, the change in the quantity of the latter may be used to determine the extent of viral degradation. Thus, the gain in the area under the fluorescence graph of free nucleic acids fraction after a given degradative process can be used as a measure of the extent of degradation. Consequently, percent degradation is defined, as this gain in area divided by the area of total nucleic acids from the original sample, that is

$$
\% V D=\frac{A_{d}-A_{f}}{A_{T}} \times 100 \%
$$

where $\% V D$ is percentage of viral degradation, $A_{d}$ is area underneath the graph of nucleic acids peak after degradation, $A_{f}$ is area underneath the graph of free nucleic acids peak and $A_{T}$ is area underneath the graph of total nucleic acids peak. We applied our method to measure percent viral degradation of the viral sample due to a number of processes commonly encountered during viral preparation, storage or use, and the results of these analyses are tabulated in Table $\mathbf{1 .}$

Sonication: Sonication or ultrasonic treatment of proteins is often used as a technique for solubilizing these components before gel analysis or other applications (Wu et al, 2009). Furthermore, it is desirable to increase the solubility of VSV particles prior to analysis, specifically, to break down virus aggregates that could decrease the infectivity of viral sample; for example causing an underestimation of viral concentration during plaqueforming assays. Therefore, we set about analyzing the effects of ultrasonic treatment on 
viral samples using an ultrasonic bath with $40 \mathrm{kHz}$ power. The electropherograms for samples treated as such for two different time periods are presented in Figure 5A. It can be seen that the intensity of spiked peaks corresponding to the virus decreases to a great degree for both time periods. However, there is a great increase in the fluorescence of the nucleic acid fraction indicating the breakdown of a significant portion of virus. According to the results presented in Table 1, 28\% and 32\% of the virus were degraded due to 5 and 15 minutes of ultrasonic treatment, respectively. It is intriguing that the degree of degradation is similar for both time periods.

Extensive vortexing: Vortexing is another commonly used procedure for solubilizing insoluble components or pellets after centrifugation. The same analysis as described above was applied to samples vortexed continuously for 10 or 25 minutes, for which the electropherograms are shown in Figure 5B. In these samples, similar to those treated ultrasonically, the intensity of spikes decreased, albeit not as dramatically. Furthermore, these spikes demonstrated a decrease in their eletrophoretic mobility. This shift cannot be attributed to experimental variations since nucleic acid peaks of all three samples maintained similar mobilities. Since in the case of negatively charged analytes an increase in eletrophoretic mobility indicates a decrease in size, this could imply formation of partially degraded virions due to the extensive vortexing. Similar to the previous procedure, the fluorescence of nucleic acid peak was significantly enhanced, evidently due to $22 \%$ and $41 \%$ viral degradation for the aforementioned conditions, respectively. In this case, however, the amount of degradation seems to correlate to the amount of time each sample was vortexed. 


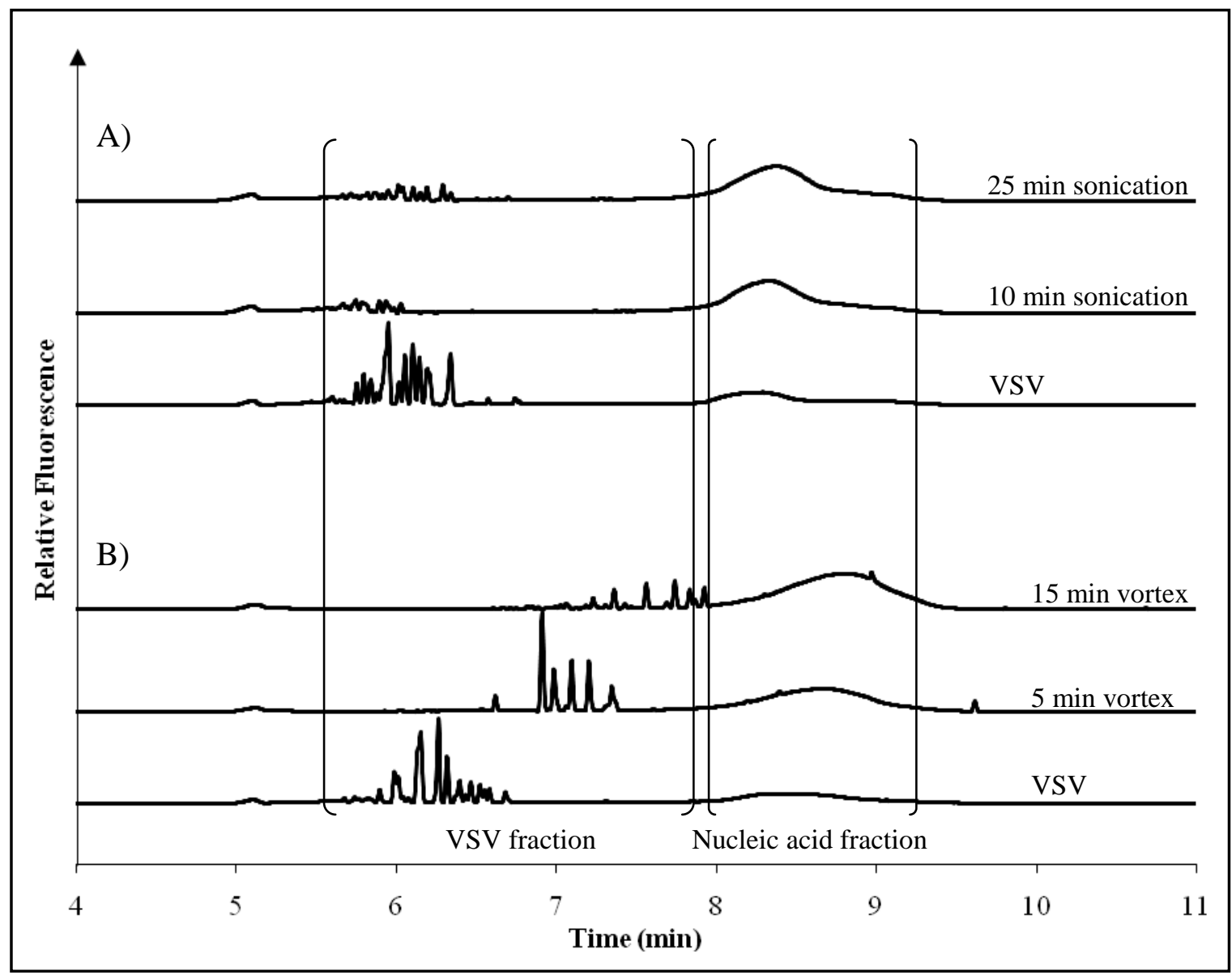

Figure 5. Increase in the nucleic acid peak of VSV samples (bottom in both panels) due to A) sonication for 5 (middle) and 15 (top) minutes, and B) vortexing at maximum speed for 10 (middle) and 25 (top) minutes. See methods for more details. 
Determination of host DNA contamination: Regulatory guidelines limit the amount of DNA that is allowed in human dose of viral therapeutics. Consequently, we broadened the application of our method to facilitate the quantification of contaminating host DNA in the viral sample. We employed a similar approach to that developed for viral concentration determination. Taking advantage of the stability of DNA in basic conditions compared to RNA, the lysed viral samples were incubated with $\mathrm{NaOH}$ to hydrolyse viral RNA and quantify the DNA contamination left behind. To this end, the minimum conditions for degrading RNA while keeping the majority of DNA were determined experimentally. As can be seen in Figure 6A (and from data not shown), incubating standard rRNA with $50 \mathrm{mM}$ of $\mathrm{NaOH}$ at $37^{\circ} \mathrm{C}$ did not completely degrade RNA, as was the case with concentrations smaller than $50 \mathrm{mM}$. However, at $60^{\circ} \mathrm{C}$, all the RNA was removed while DNA did not seem to be significantly degraded under the same conditions (Figure 6B). Nevertheless, all DNA standard samples used in constructing the DNA standard curve of Figure 7 were incubated with $50 \mathrm{mM}$ of $\mathrm{NaOH}$ under the same conditions to correct for any possible loss. Furthermore, similar to the rRNA standards, a curve was fit to the recorded data using non-linear regression, minimizing the square of difference, to obtain the following relationship

$$
R F U=\exp \left(2.26 \cdot[R N A]^{0.15}+5.12 \times 10^{-4} \cdot[R N A]-4.06\right)
$$

This relationship was applied to interpolate the concentration of contaminating DNA within the sample reported in Table 1. While this concentration appears much higher than regulatory guidelines, it must be noted that a) this particular batch of viruses was prepared for applications that did not require high levels of purification (i.e. using sucrose 


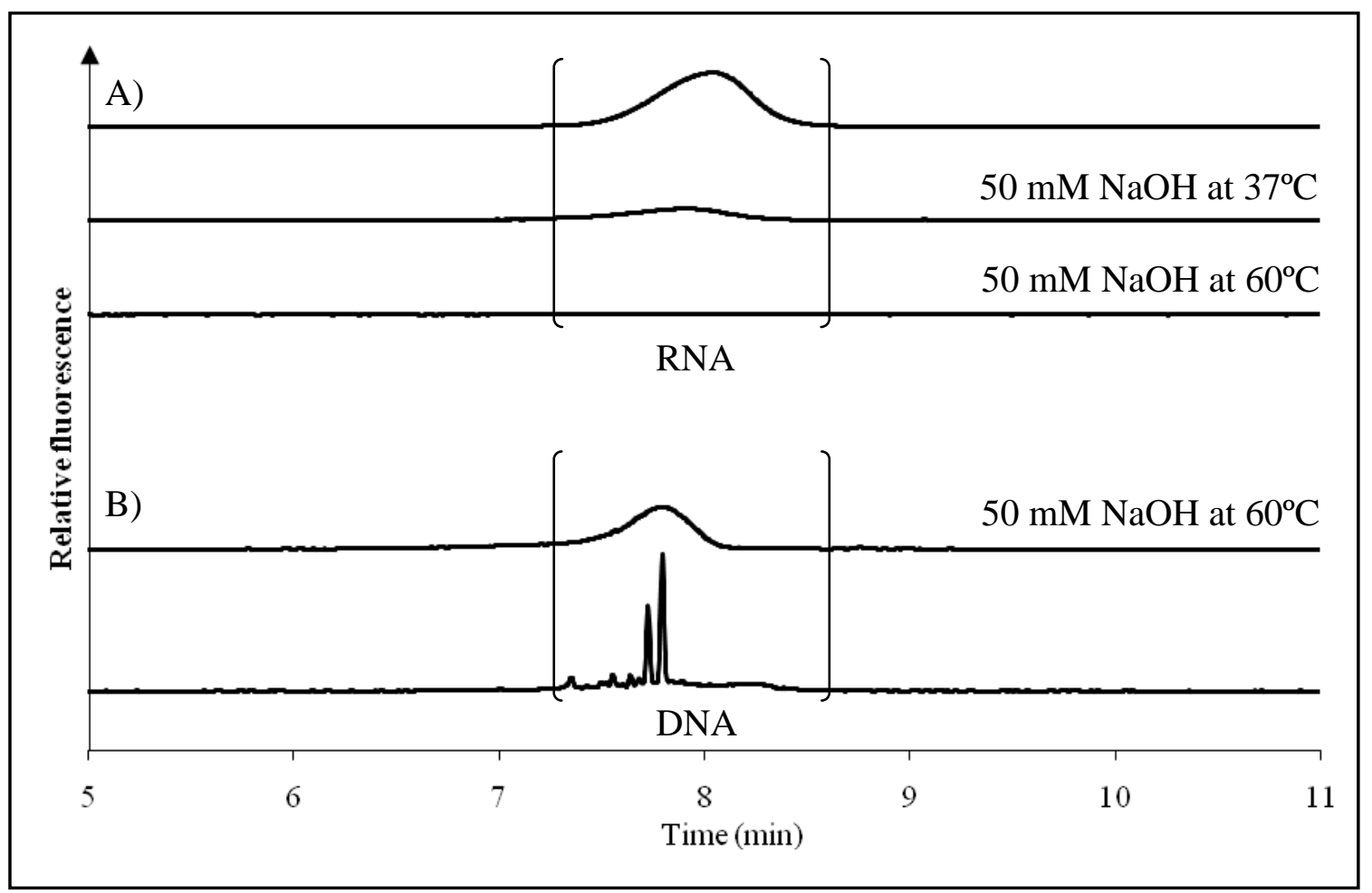

Figure 6. Control for the alkaline hydrolysis of RNA and DNA, whereby, A) fluorescence of $42 \mu \mathrm{g} \mathrm{mL}^{-1}$ of RNA (top) decreased (middle) or was completely lost (bottom) due to incubation with $50 \mathrm{mM} \mathrm{NaOH}$ at $37^{\circ} \mathrm{C}$ or $60^{\circ} \mathrm{C}$, respectively. B) Fluorescence of $42 \mathrm{ug} \mathrm{mL} \mathrm{m}^{-1}$ of DNA (bottom) was not significantly affected after treatment with $50 \mathrm{mM} \mathrm{NaOH}$ at $60^{\circ} \mathrm{C}$ (top). 


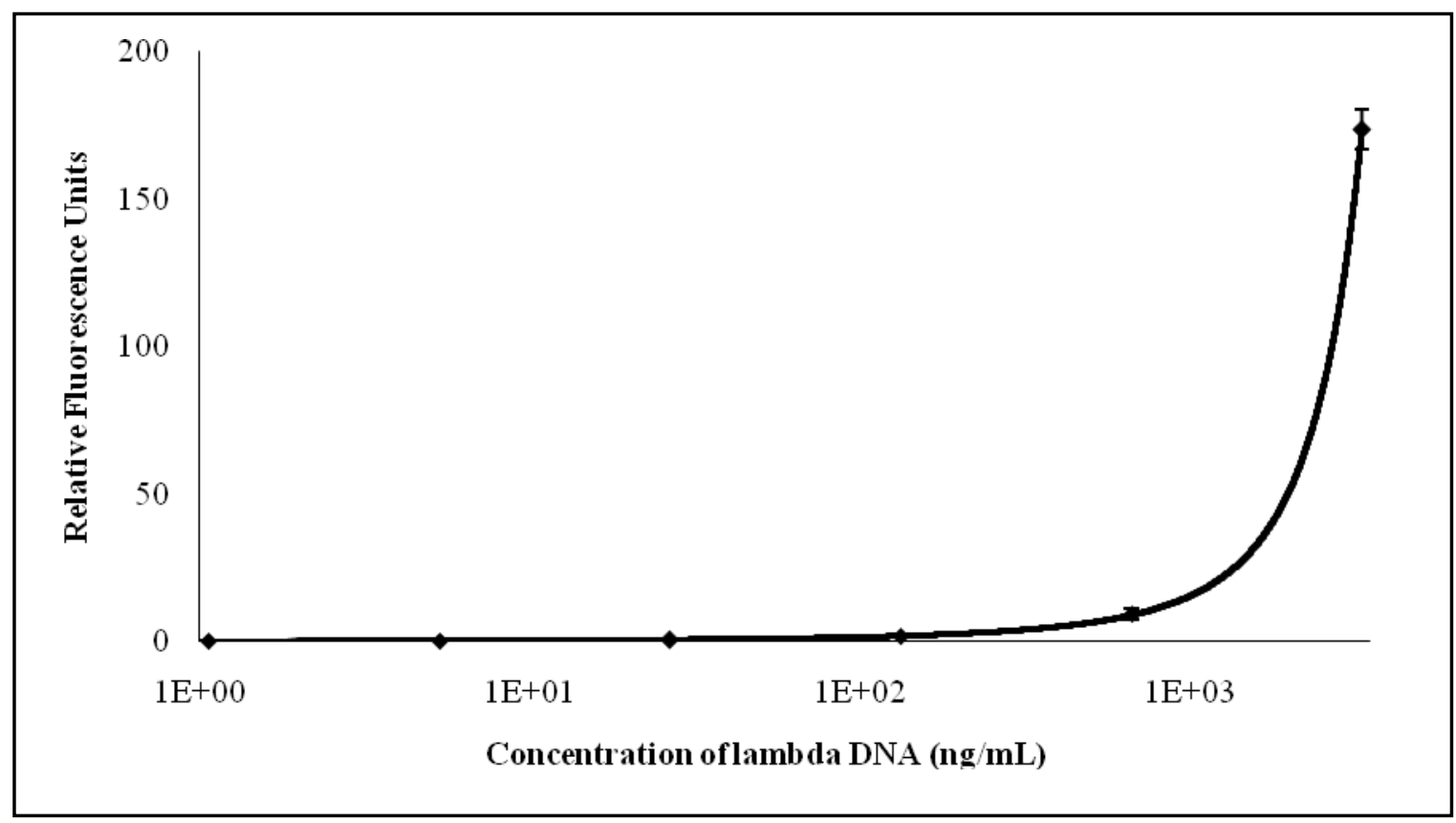

Figure 7. Increase in fluorescence of YOYO-1 dye bound to various concentrations of lambda DNA. Non-linear regression was used to fit a line to experimental data points, and it is used to interpolate the equivalent concentration of host contaminating DNA based on the latter's fluorescence. 
gradient purification (Diallo et al, 2012), and thus, would have contained greater amounts of host DNA contamination, and b) for concentrations of virus used in therapeutic doses that are diluted 1000 -fold or more (i.e. $10^{7}$ PFUs or less), which are common clinical values for oncolytic virus therapeutics (Breitbach et al, 2011), even such unpurified viral preparations would conform to said guidelines.

Quantification of viral samples using NanoSight: NanoSight is a visualization and measurement system for nanoparticles, which relies on the Nanoparticle Tracking Analysis (NTA) technology. NTA technology and its application in measuring the concentration of nanoparticles have been described, in detail, elsewhere (Malloy and Carr, 2006). We used NanoSight system to quantify the amount of virus present in viral samples from the first batch as a comparison to our developed methodology. This method has been used previously to determine the concentration of adenovirus and poxvirus samples with a detection range of $10^{7}-10^{9}$ ivp $\mathrm{mL}^{-1}$ (Mironov et al, 2011; Du et al, 2010).

Application of NanoSight analysis to our viral sample yielded a concentration of (1.7 \pm $0.2) \times 10^{13}$ particles $\mathrm{mL}^{-1}$. The highest number of particles was detected at a size of 138 $\mathrm{nm}$, as seen in Figure A2, by the instrument. This size corresponds to the average crosssectional dimensions $(70 \mathrm{~nm} \times 200 \mathrm{~nm})$ of a VSV particles. The stretch of the graph to the right and a slight shoulder observed there are probably caused by aggregate formation resulting from detection of larger particles. 


\section{Conclusion}

We have successfully tailored a new method of quantitating RNA viruses using high sensitivity laser induced fluorescence capillary electrophoresis and applied it to a number of oncolytic VSV samples with promising results. This method, in conjunction with one developed previously for quantification of DNA viruses, will have the potential to quantify the concentration of any virus preparations with medium to high titer range. Furthermore, we have developed a simple way for determining the amount of DNA contamination and successfully used it to accomplish this task. Given a one-time generation of two standard curves (one for DNA and another for RNA), viral qCE allows for an integrated approach for determination of viral concentration and that of contaminating host DNA in three simple steps spanning one afternoon with minimal handling time. It is possible to conceive a future amelioration of this method by using capillary electrophoresis coupled to mass spectrometry for dye-free detection of the nucleic acids in the sample and differentiation between DNA contamination and viral RNA in one step. 


\section{References}

Balachandran, S.; Barber, G. IUBMB Life 2000, 50, 135-138.

Barber, G. Oncogene 2005, 24, 7710-7719.

Børsheim, K. Y.; Bratbak, G.; Heldal, M. Appl Environ Microb 1990, 56, 352-356.

Breitbach, C. J.; Burke, J.; Jonker, D.; Stephenson, J.; Haas, A. R.; Chow, L. Q. M.;

Nieva, J.; Hwang, T.-H.; Moon, A.; Patt, R.; Pelusio, A.; Le Boeuf, F.; Burns, J.; Evgin, L.; De Silva, N.; Cvancic, S.; Robertson, T.; Je, J.-E.; Lee, Y.-S.; Parato, K.; Diallo, J.-S.;

Fenster, A.; Daneshmand, M.; Bell, J. C.; Kirn, D. H. Nature 2011, 477, 99-102.

Bustin, S. A. J Mol Endocrinol 2002, 29, 23-39.

Cary, Z.; Willingham, M.; Lyles, D. J Virol 2011, 85, 5708-5717.

Clarke, D.; Cooper, D.; Egan, M.; Hendry, R.; Parks, C.; Udem, S. Springer Semin Immunopathol 2006, 28, 239-253.

Cobleigh, M.; Buonocore, L.; Uprichard, S.; Rose, J.; Robek, M. J Virol 2010, 84, 75137522.

Collins, M. K. Practical Molecular Virology; Humana Press: New Jersey, 1991; Vol. 8.

Cosa, G.; Focsaneanu, K. S.; McLean, J.; McNamee, J.; Scaiano, J. Photochem photobiol 2001, 73, 585-599.

Cureton, D. K.; Massol, R. H.; Whelan, S. P. J.; Kirchhausen, T. PLoS Pathog 2010, 6, e1001127.

Diallo, J.-S.; Vähä-Koskela, M.; Le Boeuf, F.; Bell, J. Meth Mol Biol 2012, 797, 127140.

Du, S.; Kendall, K.; Morris, S.; Sweet, C. J Chem Technol Biot 2010, 85, 1223-1228.

Dulbecco, R.; Freeman, G. Virology 1959, 8, 396-397.

Ebeling, W.; Hennrich, N.; Klockow, M.; Metz, H.; Orth, H. D.; Lang, H. Eur J Biochem 1974, 47, 91-97.

Hierholzer, J.; Killington, R. Virology methods manual 1996, 25-46.

Galanis, E. Nature 2011, 477, 40-41. 
Geisbert, T.; Daddario-DiCaprio, K.; Lewis, M.; Geisbert, J.; Grolla, A.; Leung, A.; Paragas, J.; Matthias, L.; Smith, M.; Jones, S.; Hensley, L.; Feldmann, H.; Jahrling, P. PLoS Pathog 2008, 4, e1000225.

Johnson, I.; Spence, M. T. Z. The Molecular Probes Handbook: A Guide to Fluorescent Probes and Labeling Technologies, $11^{\text {th }}$ Edition; Life Technologies, 2010.

Karger, B. L. Nature 1989, 339, 641-642.

Knipe, D. M.; Howley, P. M. Fields Virology, $5^{\text {th }}$ edition; Lipponcott Williams \& Wilkins, 2011.

Kremser, L.; Blaas, D.; Kenndler, E. Electrophoresis 2004, 25, 2282-2291.

Kremser, L.; Okun, V. M.; Nicodemou, A.; Blaas, D.; Kenndler, E. Anal Chem 2004, 76, 882-887.

Kremser, L.; Blaas, D.; Kenndler, E. Electrophoresis 2009, 30, 133-140.

Krylova, S. M.; Rozenberg, D.; Coulton, J. W.; Krylov, S. N. Analyst 2004, 129, 1234 1237.

Lambeth, C. R.; White, L. J.; Johnston, R. E.; de Silva, A. M. J Clin Microbiol 2005, 43, 3267-3272.

Majid, A.; Ezelle, H.; Shah, S.; Barber, G. J Virol 2006, 80, 6993-7008.

Malloy, A.; Carr, B. Part Part Syst Charact 2006, 23, 197-204.

Mironov, G.; Chechik, A.; Ozer, R.; Bell, J.; Berezovski, M. Anal Chem 2011, 83, 54315435.

Mocé-Llivina, L.; Lucena, F.; Jofre, J. Appl Environ Microb 2004, 70, 2801-2805.

McCord, B.; Hartzell-Baguley, B.; King, S. Meth Mol Biol 2008, 384, 415-429.

Nguyen, T.-A.; Tumilasci, V.; Singhroy, D.; Arguello, M.; Hiscott, J. Cell Microbiol 2009, 11, 889-897.

Rainsford, E. W.; Harouaka, D.; Wertz, G. W. J Virol 2010, 84, 1741-1751.

Russell, S. Cancer Gene Ther 2002, 9, 961-966.

Russell, S. J. Encyclopedia of Life Sciences, Nature Publishing Group 2006. 
Sotelo-Silveira, J. R.; Calliari, A.; Cárdenas, M.; Koenig, E.; Sotelo, J. R. J Neurobiol 2004, 60, 187-196.

Stojdl, D.; Lichty, B.; tenOever, B.; Paterson, J.; Power, A.; Knowles, S.; Marius, R.; Reynard, J.; Poliquin, L.; Atkins, H.; Brown, E.; Durbin, R.; Durbin, J.; Hiscott, J.; Bell, J. Cancer Cell 2003, 4, 263-275.

U.S. Department of Health and Human Services. Minutes of Recombinant DNA Advisory Committee meeting 09/9-10/08. 2008 National Institute of Health.

U.S. Department of Health and Human Services. Minutes of Recombinant DNA Advisory Committee meeting 12/3-4/08. 2008 National Institute of Health.

van Aken, W. G.; Dobbelaer, R.; Fuchs, F.; Grachev, V.; Homma, A.; Kurata, T.; Löwer, J.; Minor, P.; Reigel, F.; Vyas, G. N. WHO Expert committee on biological standardization technical report series. 2007 World Health Organization.

Wu, Y.; Zhou, J.; Zhang, X.; Zheng, X.; Jiang, X.; Shi, L.; Yin, W.; Wang, J. Proteome Sci 2009, 7, 38. 


\section{Appendix}

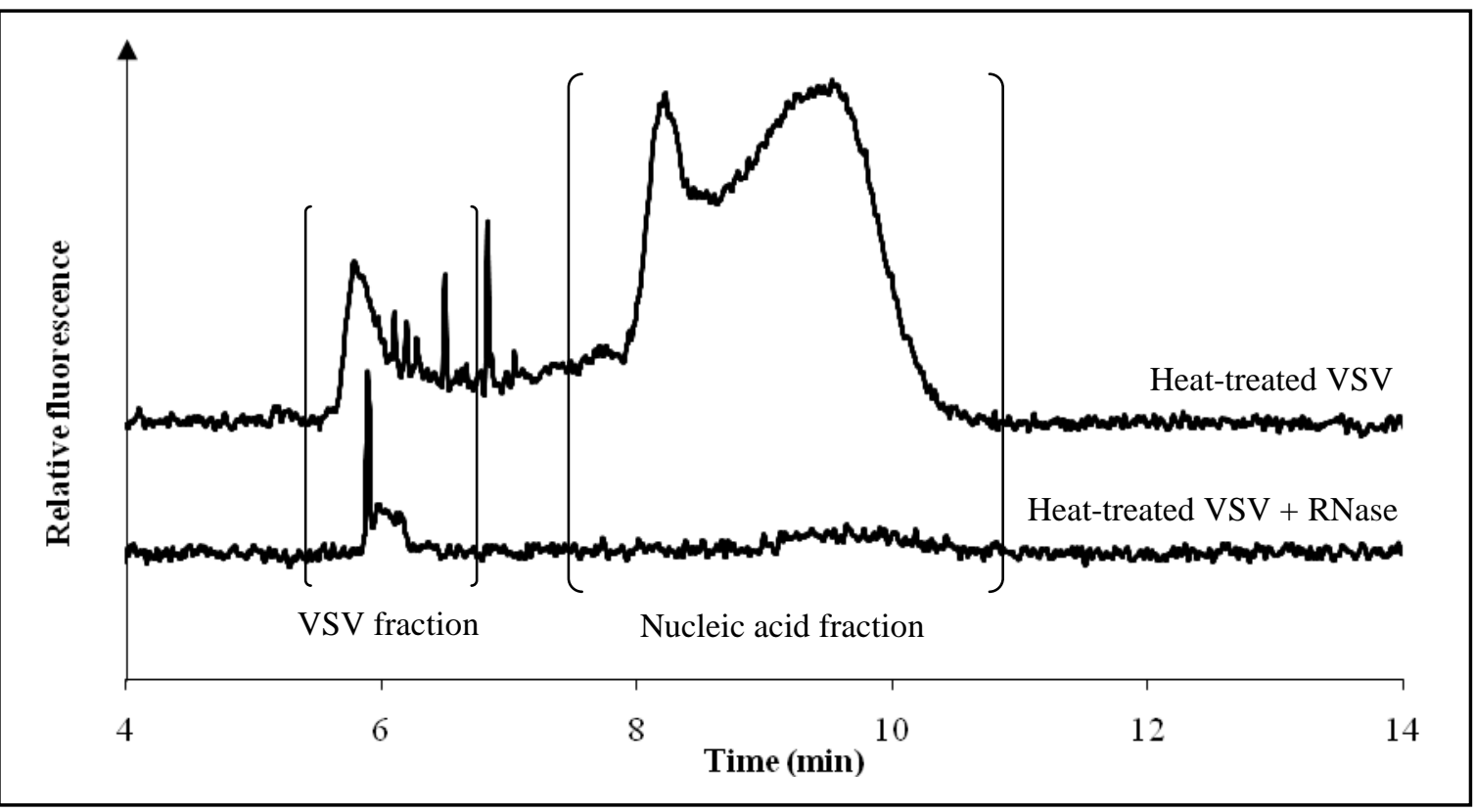

Figure A1. Incubating VSV at $95^{\circ} \mathrm{C}$ for up to 4 hours (top) only partially produces naked RNA molecules, as was confirmed by treating a sample prepared in this manner with RNase (bottom) revealing a small peak with the same electrophoretic mobility as the intact virus. 

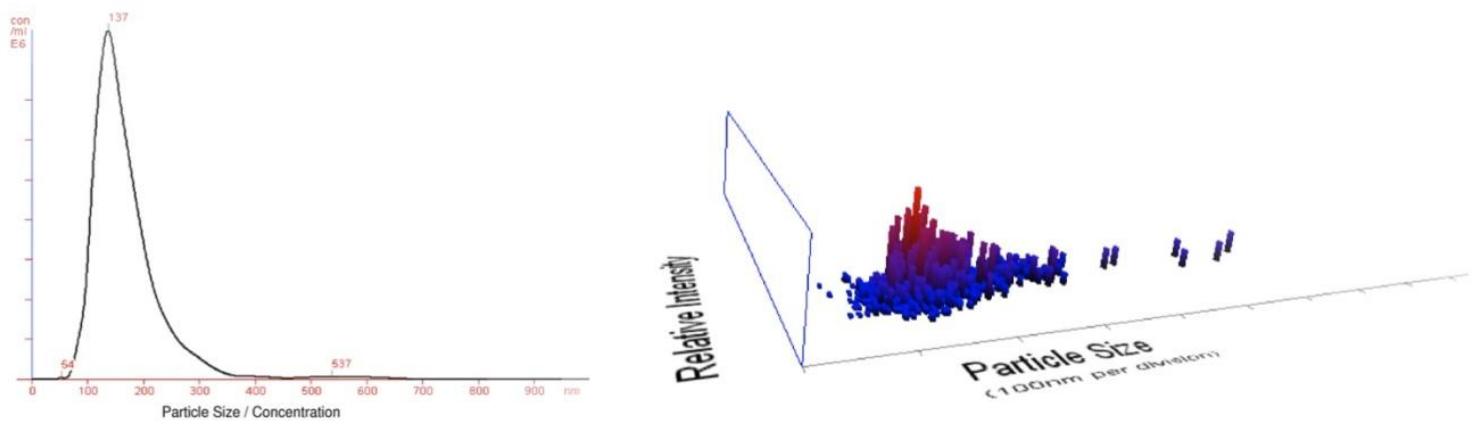

Figure A2. Size and concentration distribution, generated by NTA software, of VSV particles in a representative sample. 